\title{
Financing, Incubating, Coaching, and the Cluster Effect
}

\author{
Fritz R. Bühler* and Christian Suter
}

\begin{abstract}
More innovation financing, incubating and coaching would be helpful for European biotechnology. Venture capital is available for all stages of biotech company development, providing companies are innovative and of high quality. Several venture funds are active in the BioValley. To compensate for the shortcomings of management experience, a low-cost portfolio of integrated services could be provided by seasoned managers but the system has to be created, managed, and paid for by the small companies. Such shortcomings facing young companies can be overcome by seed financing, incubating and coaching, and providing a dynamic regional biotech/life sciences development organization leading to a cluster effect. This allows much better use of available assets including sparse financial means.
\end{abstract}

Keywords: Biotechnology industry · Cluster effect · Life sciences · Stock exchange $\cdot$ Venture capital

\section{Introduction}

There was a favorable message coming from numerous industry reports earlier in the year - such as Ernst \& Young's Global Biotechnology Reports Series - that there is again positive earnings growth, increased approvals of first in class biologicals, positive clinical trial results and favorable deals between small biotech pharma and big pharma. These are leading to reinvigorated investor interest, but most of this evidence is US-based. In Europe, the situation is not so rosy and although some IPOs have happened, the overall market performance and successful product news have been far less prominent, which leaves many companies with less than two years cash in the bank and, as another symptom, a financial environment which is not too favorable for the funding of biotech start-ups.

\footnotetext{
${ }^{\star}$ Correspondence: Prof. Dr. med. F.R. Bühler BioValley Basel

Blumenrain 23

$\mathrm{CH}-4051$ Basel

Tel.: +416126576 54

Fax: +41612657655

E-Mail: fritz.buhler@unibas.ch
}

This financial bottle neck has the greatest impact on some European countries where in the last ten years too many small biotech companies have been founded with too much financial support in too short a time. In other systems, where public funding was sparsely available, fewer biotech companies were founded, mostly with a better chance for survival i.e. they were based on better quality, more stringent business plans and therefore better fundability and early growth.

The remedy to some of the weak spots in the Central European biotechnology industry may be related to more innovation financing and related key measures, i.e. incubating and coaching - the provision of 'smart money'.

\section{Financing}

Venture capital is available for all stages of biotech company development, providing companies are innovative and of high quality. Venture capitalists' (VCs) decisions balance the risk of an investment as assessed through careful quality checks and due diligence appraisal of a target biotech company. Aspects evaluated include concepts and medical need of drug/devices, research, patents, manufacturing, preclinical and clinical development, business/market development, as well as - and obviously important for the risk taker - projections of potential return on investments. Such returns or exits can be realized by VCs most frequently through an initial public offering (IPO or going public at a Stock Exchange), an acquisition or a merger. It should not be forgotten that it is people who sit on either side of an investment, and their interactive 'chemistry' and mutual trust are important ingredients for final agreements.

After the last IPO window in 1999/2000 and the subsequent baisse, the short-term future of the biotech industry and market once again looks more promising:

- Blue chip markets have regained momentum in recent months e.g. NYSE gained $35 \%$.

- Biotech companies' stocks have increased, e.g. NASDAQ biotechnology index gained $44 \%$.

- Towards the end of 2003 seven IPOs were carried out; these are performing reasonably well in the public market, with stock prices on average floating around the issue prices.

- In 2004, so far around 30 new (some high quality) biotech companies IPOs came through a successful IPO in the US, while in Europe there were only seven spread over several stock exchanges e.g. Swiss, London, Stockholm, Copenhagen, and Frankfurt. Seasoned biotech investors are back with an understanding of long-term value creation.

- From the last to the present IPO window investors' interests have shifted from technology-platform based companies towards companies closer to the market (and financial returns), i.e. companies 
already at the proof of concept stage and with assets well into clinical development. Clinical drug development and manufacturing are crucial to sustaining innovation, but they are often badly understood.

- The USA is still trailed by Europe, but here too, individual biotech companies are beginning to prepare their public offering e.g. at the Swiss or London Stock Exchange.

In the longer-term, there is no doubt that there is a great future for the life sciences industry in general and the biotechnology (small pharma) industry in particular. At least 1200 diseases need new or better treatments, and the ageing population is increasing. Technology platforms now deliver new drugs, and more biotechnology based drugs pass stringent approval regulations. Per major drug, the development process now costs more than $€ 1$ billion, with corresponding drug price increases. Innovation has its price, and returns pave innovation. Current biotechnology innovation has created worldwide annual sales of about $€ 20$ billion. This in turn has brought new life to big pharma industries as well as great incentives for their partnering biotech pharma SME industry.

Europe has around 1300 biotech companies, matching numbers in the USA. However, the biotech industry - as well as the private equity/VC industry - in Europe is only 15 years old and still some 10 years behind the mature industry in the USA. Despite this, 680 million Euros worth of new funds were raised in 2003. 616 million Euros were invested into new deals and 52 early-stage companies were financed, together representing $27 \%$ of all European deals. This looks promising, but greater efforts must be made to enhance the competitiveness and the performance curve of the European biotechnology industry.

In our Central European financial environment with access to hundreds of millions of Euros in risk capital, there is still a lack of funds for seeding and starting-up, which represent the highest risk and lowest chance of return. This very first financing step is most crucial, and only few investment organizations deal with this situation.

In our BioValley - Swiss Biotech Cluster we are fortunate to have the EVA, Erfindungs Verwertung AG, as well as Bio-
Medinvest (which recently closed at CHF 100 Mio.) for seed and start-up investments. Several other venture funds including the Novartis Venture Fund also do early investments. The BioValley Investors Club helps to prepare the grounds for small biotech-investor interaction.

\section{Incubating}

Most universities have a technology transfer organization as more universities examine ways to commercialize their research. Only few have seed funds available, which in our situation come from private equity funds (see above) and rarely from business angels, private individuals willing to take this risk! In founding a new company the entrepreneur is bound to encounter several hurdles. The first is the difficulty of finding the right premises, e.g. labs in a Biopark. The second hurdle is to find the right services which help to make the business not too expensive.

Ideally, wet lab space should be available at the seed stage and this is often provided by the university or by the mother company. This is used as a spring board, but at some point the transition from the safe harbor into a new facility has to happen, often in a matter of months.

Therefore, fully equipped wet labs, 'ready to go', should be available, ideally in a biopark environment. The construction of these early laboratory facilities is way beyond the financial means of a company in the start-up phase and should be provided by the biopark. Here is an important role for public funding. There is no question that the usual paradigm of planning lab space in a biopark, which traditionally requests the majority of space to be prerented before the construction even starts, greatly hinders early growth of a biotech company. The best technology transfer organizations and cluster development organizations do not help the early steps of biotech small enterprises if there are no incubators.

\section{Coaching}

Most biotech companies are started by scientists from academia or by employees with purely scientific roles in existing com- panies. Almost overnight this person has to be chief scientist, entrepreneur, personnel manager, lab manager, and accountant. The Central European biotechnology industry is not even ten years old and short of management experience compared with the US. The availability of experienced managers is the final single factor deciding the credibility of the business plan and the investors' financing decision.

These shortcomings could be tackled in different ways. For example one could establish a management course/school to cover the ardent needs of our biotech industry. Alternatively, cluster organizations could provide integrated services to support a whole list of functions including financing and accounting, purchasing, product development, counseling, language services etc. Such services provided by a one-stop-shop could serve in a highly economical way a whole group of small enterprises who otherwise cannot afford true quality i.e. hiring individual experts for each function. Such a low-cost portfolio of integrated services could be provided by seasoned managers (in the pension age) but the system has to be created, managed, and paid for by the small companies.

\section{The Cluster Effect}

Being part of an incubator or cluster provides a powerful force - the cluster effect! The companies are in proximity exchanging ideas, expertise and equipment and offering services to each other. There is a natural opportunity to change jobs and investors located in the cluster will truly care about their companies. The cluster makes a sizeable contribution to companies' sustainability and growth; local clusters embedded in national and international networks are especially valuable.

Elimination of such shortcomings through seed financing, incubating and coaching and providing a dynamic regional biotech/life sciences development organization will lead to a cluster effect with much better use of available assets including sparse financial means.

Received: October 25, 2004 